\title{
ESQUISTOSSOMOSE: 1.000 PACIENTES TRATADOS *
}

\author{
Pedro Aquino Noleto ** Paulo F. Neyes ***, Oclaviano Magalhães *** \\ e José Maria Silva ****
}

\begin{abstract}
Os autores relatam sua experiência com o hycanthone em 1.000 pacientes de esquistossomose mansônica, até agora tratados no Hospital de Clínicas da Universidade do Estado da Guanabara. São pacientes oriundos de áreas endêmisas do Pais, especialmente do nordeste e sudeste, $53,9 \%$ do sexo masculino $e$ 46,1\% do sexo feminino, de idade entre 5 e 63 anos. A forma clinica predominunte da parasitose foi a hépato-intestinal $(96,8 \%)$. O medicamento foi administrado em dose única, na razâo de $3 \mathrm{mg} / \mathrm{kg}$ de peso corporal, a $33.6 \%$ de pacientes internados e a $66.4 \%$ em regime de tratamento ambulatorial. Os ni$v e i s$ séricos das transaminases, determinados, para confronto, antes e depois do usu do produto, em 60 dos pacientes internados, não se alteraram, ou apenas sofreram elevações inexpressivas. Não houve efeitos colateriais em $42,3 \%$ dos pxc'entes. Nos demais, esses efeitos foram de pequena e média intencidade, duraram apenas o $1^{\circ}$ dia, na maioria das vezes, e consist ram, especialmente, de náuseas e de vômitos. O controle de cura parasitária estabelecido compreendeu 4 exames de fezes - aos 30,60, 90 e 120 dias do emprego do medicamento, 0 que já se fez em 330 pacientes (33\%), com 99\% de cura. Incluida a biópsia retal, sempre que foi possivel, por ocasiáo do 4 o exame de fezes, o esquema funcionou até agora em 97 pacientes (9,7\%), dos quais 92 (94\%) estão curados, segundo esse critério. $O$ presente trabalho confirma a ação esquistossomicida do hysanthone, bem como sua boa tolerabilidade, inclusive no que se refere ao hepatócito. Os doentes, entretanto, devem ser criteriosamente seleci nados, tendo-se em vista as contra-indicaçôes conhecidas, de modo e: pecial em relação ao figado.
\end{abstract}

A importância da esquistossomose nas regiōes endêmicas do mundo é crescente e preosupa governos e particulares. Além da reconhecida morbidade, que assume aspectos e graus diversos, freqüentemente graves, a expansão da endemia, à custa do próprio homem, confere ao complexo médico-sanitário da parasitose feição mais grave aind̆a e perspectivas mais sombrias. No Brasil, o fenômeno é patente: migrações internas aceleradas, em função do sis- tema de transporte, hoje ao alcance de todos, ocorrem como em nenhuma outra época da nossa história.

As más condiçōes de vida do povo, em contato com águas poluídas, nas áreas infestadas, somadas aos graves e sérios problemas inerentes à profilaxia - vasto programa de engenharia sanitária e de recuperação social do homem - fazem da esquistossomose um tema de interesse público da maior atualidade, que deve figurar,

* Traba!ho do Departamento de Medicina do Hospital de Clínicas da UEG. Apresentado no X Congresso dz Sociedade Brasiletra de Medicina Tropical.

* Professor Titular Interino. Professor-adjunto de Clínica Médica.

*** Assistentes.

*⿻一𠃋十 Clínico do INPS.

Recebido para publicação em 5-8-74. 
prioritariamente, ao lado de outros, no que se refere às populações do interior, em qualquer esquema de desenvolvimento nacional.

Quantos são os esquistossomóticos do Brasil, hoje, não sabemos ao certo, mas a cifra gira em torno de $8 \%$ da população do País, ou seja, 8 milhões de pacientes, entre os quais se contam hipo-desenvolvidos, inválidos, em grau maior ou menor, e aqueles que, em número elevado, sucumbem em plena juventude ou quando mal atingem a maturidade.

Assim, o presente trabalho é uma contribuiçāo que vem somar-se ao esforço de muitos para a solução de tão relevante problema de saúde coletiva. Empreendido no Estado da Guanabara, seu alcance torna-se maior, porquanto atende ao aspecto epidemiológico da parasitose, de capital importância quando se atua fora de áreas endêmicas. Reflete, por outro lado, nossa experiência no Hospital de clínicas da UEG com o mais novo agente terapêutico, em uso, da Doença de Manson-Pirajá da Silva.

\section{PACIENTES E METODOS}

Os pacientes referidos neste trabalho, em número de 1.000 , provêm na sua quase totalidade de áreas endêmicas de esquistossomose em nosso País; sāo de ambos os sexos e de idade entre 5 e 63 anos. Sem queixas, muitos deles, ou com queixas digestivas variáveis, de pequena monta, ou ainda com manifestaçōes clínicas sugestivas da parasitose, tais pacientes foram submetidos a exames de fezes, e parte deles, após coproscop:a negativa, também à biópsia retal para pesquisa de ovos de $S$. mansoni. Estabelecido o diagnóstico, que compreendeu as formas hépato-intestinal $(96,8 \%)$ e hépato-esplênica $(3,2 \%)$, seguin-se o exame clínico para a avaliação do estado geral de saúde dos pacientes, tendo-se em vista as contra-indicaçōes do medicamento a ser empregado, o Methanosulfonato de Hycanthone, administrado em dose única, na razão de $3 \mathrm{mg} / \mathrm{kg}$ de peso, até $200 \mathrm{mg}$, por via intramuscular. Em $66,4 \%$ dos pacientes o tratamento foi ambulatorial; enquanto que os $33,6 \%$ restantes receberam a medicação hospitaliza- dos, seja em virtude de supostos riscos, seja porque necessitassem de tratamento prévio de outros estados mórbidos. Feita a medicação, o doente era observado, submetido a dieta adequada, se necessário, e a repouso relativo, permanecendo afastado do trabalho pelo menos no 19 dia. No intuito de pesquisar possiveis danos hepáticos causados pelo medicamento, determinamos a atividade das transaminases séricas em $\mathbf{6 0}$ desses pacientes, divididos em 3 grupos de 20 , antes e 24, 48 e $72 \mathrm{~h}$. após a medicação. respectivamente. $O$ controle de cura parasitária constou de 4 exames de fezes: ao fim do $19,2 \%, 39$ e 49 mês do uso do remédio. Um número menor de pacientes foi controlado com biópsia retal, além da coproscopia. (Tabelas I, II e III) .

\section{RESULTADOS E CONCLUSOES}

Desta série de pacientes tratados, apenas $33 \%$ terminaram até agora o controle de cura parasitária, segundo o critério adotado. Estão curados, de acordo com esse critério, $99 \%$ deles, ou seja, somente 3 pacienttes continuaram eliminando oves viáveis de $S$. mansoni. Em 97 desses 330 pacientes, entretanto, fizemos biópsia retal, que foi positiva em 5, o que fez cair para 94 a porcentagem de cura obtida.

Não houve efeitos colaterais em $42,3 \%$ dos paciente. Nes demais, esses efeitos foram de pequena e média intensidade, duraram apenas o 19 dia, na maioria das vezes, e consistiram, especialmente, de náuseas e de vômitos. Dois dos pacientes

\section{TABELA I}

Distribuição dos 1000 pacientes tratades com Hycanthene segundo idacie, sexo e cor.

Idade

5 a 63 anos

Sexo

Mascul'no

539 casos $/ 53,9 \%$

Feminino

461 casos $/ 46,1 \%$

Cor

Branca

844 casos $/ 84,4 \%$

Preta

NOTA: Par:e dos pacientes aqui referidos foram atendidos pelos autores no Posto da SUCAM. em Sao Cristórăo, após entendimento com o Dr. Znmir de Ollveira, Chefe do Setor Guanabrrs daquele organismo. Salientamos, ainda, que no nosso ambulatórío, contamos com a valiosa coloboração da Central de Medicamentos (CEME). que forneceu o remédio para os doentes de balxo poder equisitivo. 


\section{TABELA II}

Distribuição dos 1000 pacientes tratados com Hycanthone, segundo a procedência dos pacientes e a forma clínica.

Procedência

\section{Autóctones}

N/autóctones

$3,5 \%$ $96,5 \%$

Formas clínicas

$\mathrm{Hi}$

$\mathrm{He}$
$96,8 \%$

$3,2 \%$
TABELA III

Resultados do tratamento em 1000 pacientes tratados com Hycanthone.

Dose única

$3 \mathrm{mg} / \mathrm{Kg} / \mathrm{IM}$

Regime de tratamento

$$
\text { Hosp. }
$$

$336 / 33,6 \%$

Amb.

$664 / 66,4 \%$

Controle de cura/4 meses

Ex. fezes $\quad 330 / 33,0 \%$

Biop. retal $97 / 9,7 \%$

Cura

Ex.fezes $\quad 327 / \quad 99 \%$

Biop. retal $92 / 94 \%$

\section{TABELA IV}

Efeitos colaterais observados em 1000 pacientes tratados com Hycanthone

$\begin{array}{ll}\text { MAIS FREQUENTES } & \text { MENOS FREQUENTE } \\ \text { Náuseas } & \text { Astenia } \\ \text { Vômitos } & \text { Tremores generalizados } \\ \text { Tontteira } & \text { Mal-estar geral } \\ \text { Cefaléia } & \text { Sonolência/Nervosismo } \\ \text { Dor epigástrica } & \text { Febre/Formicamento no corpo } \\ \text { Anorexia } & \text { Insônia/Desconforto abdominal } \\ \text { Diarréia } & \text { Dor torácica/Calafrio } \\ \text { Dor local injeção } & \text { Sudorese/Alg as }\end{array}$

AUSENCIA DE EFEITOS COLATERAIS

$42,3 \%$

medicados no ambulatório, pela manhã, voltaram ao Hospital à noite, por causa de vômitos. Internados e medicados, obtiveram alto no dia seguinte, assintomáticos. Os niveis séricos das transaminases, nos 60 pacientes em que foram determinados, não se alteraram com a medicação, ou apenas sofreram elevações inexpressivas. (Tabelas III e IV).

Assim, as conclusōes do presente trabaIho confirmam a ação esquistossomicida do Hycanthone, já bem conhecida, inclusive no nosso meio, do mesmo modo que sua boa tolerabilidade, de maneira geral, afastadas, necessariamente, as contra-indicaçōes existentes e observados os devidos cuidados na vigência do tratamento. Esta a experiência que resultou na presente observação.

\section{COMENTARIOS}

Importada da Africa, como se acredita, com o tráfico de escravos, a esquistossimose mansônica encontrou no Brasil condições naturais para desenvolver-se: o meio físico e a prasença indispensável do hospedeiro intermediário do Schistosoma, o caramujo. Os hábitos de vida das populaçōes rurais, impostos pelo estado de subdesenvolvimento reinante, e ainda a atividade agrícola dos habitantes, como a cultura de cana-da-açúcar, - em terreno úmido, como convém ao caramujo - vieram completar os requisitos ideais que tornariam inevitável a implantaçãc da parasitose em nosso País, tal como ocorreu. Do Nordeste, para onde foi maior, no início, o fluxo de escravos, a endemia expandiu-se, 
levada pelo homem; nas suas andanças, atingiu o sudeste e o centro, e hoje ameaça o País todo. O próprio desenvolv mento nacional a que assistimos, as facilidades de trannsporte cxistentes e a política de colonizaçầo do governo respondem por essa expansão, que, todavia, em última análise, val depender da presença do molusco, elo dà cadeia epidemiológica da parasitose.

No capitulo da terapêutica, as investigaçōes na esquistossomose sucedem-se de longa data, em busca do agente especifico, que reúna alto poder curativo e baixa toxicidade. Os antimoniais trivalentes, a começar pelo tártaro emético, introduzido por Christopherson, em 1918; o Lucanthone (Miracil D), um derivado tioxantônico, e o Niridazol, da série dos nitrotiazólicos, haviam sido até há pouco os medicamentos mais usados em todo o mundo na cura da esquistossomose. Embora eficazes, estão fora de uso, em vista dos efeitos tóxicos que produzem $(6,17,19)$.

A partir de 1964, novo esquistossomicida foi incorporado à terapêutica. Trata-se do Metanossulfonato de Hycanthone, derivado hidroximetílico do Miracil $D$, do qual representa o metabólito final, obtido graças à atividade enzimática do Aspergitius sclerotiorum. Produto de pesquisa dos Laboratórios Winthrop (26), foi empregado na esquistossomose humana, primeiramente por Rosi e col. em 1965, e mais tarde, em 1967, por esses mesmos pesquisadores (20, 21). A seguir, numerosas observações foram feitas com o novo produto, por vários investigadores, inclusive na esquistossomose urinária, tal o interesse que os primeiros ensaios despertaram. No Brasil, multiplicaram-se igualmente os estudos sobre o novo quimicterapico, desde 1967, com os trabalhus de Argento e col. (2) e Katz e col. (14), e é hoje extensa a bibliografia nacional pertinente, que abrange experimentação, farmacologia clínica, e, especialmente, 0 aspecto terapêtico da parasitose, expresso ern termos de cura parasitológica $(3,7.8,9,12)$.

O mecanismo íntimo de ação dos esquistossomicidas até agora estudados, é mal conhec do. Alteraçôes metabólicas produzidas por tais compostos seriam responsávets, primeiramente, por lesões dos órgãos reprodutores dos vermes, e portanto pela interrupcão da postura de ovos, $1^{\text {a }}$ evidência clínica de atividade do medicamento.
Posteriormente, os vermes, descasalados e imobilizados, são destruídos, em conseqüência de processos degenerativo $(4,9,11,15$, $16,24,25$ ) .

Efeitos colaterais tóxicos, inerentes "a? medicação específica até - hoje empregada, têm sido o grande entrave à terapêutica da endemia. Com o Hycanthone, respeitádas as contra-indicações já conhecidas, sobretudo em relação à célula hepática, tais efeitos, embora freqüentes, são bem tolerados e predominam na esfera digestiva, representados por náuseas, vômitos e hîpórexia.

Quanto ao figado, as manifestações clinicas descritas, às vezes graves e até fatais, têm sido raras $(9,13)$. Contudo, o produto é realmente hépato-tóxico, haja vista os estudos de Andrade e col. (1), em material de necrópsia e em material de biópzia de aguiha, praticada antes e $48 \mathrm{~h}$ depois do uso do medicamento. No primeiro caso as alteraçōes histológicas foram consideradas características de hepatite tóxica aguda. No segundo, a micro:copia eletrônica revelou diversas alteraçōes estruturais hepáticas, após a administraçāo da droga. Observação interessante e útil, de cunho eminentemente prático dos mesmos pesquisadores, é que os pacientes desnutridos estão mais sujeitos aos efeitos nocivos do medicamento, no que se refere ao fígado. Independentemente desta referência específica à célula hepática, a desnutrição já constituía, na opinião g॰ral, contra-indicação ao emprego do produto.

Para o lado do sistema nervozo, os sintomas de impregnação tóxica referidos, seriam os vômitos, tidos, assim. como de origem central (10). Já em relação ao miocárdio, estudos eletrocardiográficos efetuados logo após o uso do hycanthone, não evidenciaram alterações significativas, do mesmo modo que não há na literatura referência a manifestações clínicas cárdio-vasculares atribuíveis ao medicamento (9, 18. 22).

O Hycanthone presta-se, portanto, nem só para tratamento ambulatorial, como se vem fazendo largamente, mas também para tratamento em massa, nas zonas endêmicas, como igualmente já se faz, inclusive entre nós $(3,23)$. Abre-se, desta maneira, nos dias atuais, para a terapêutica da esquistossomose, perspectiva nova, do maior alcance clínico e epidemiológico. 


\section{SUMMARY}

The authors report hier experiment with Hycanthone in a thousand patients suffering from schistosomixasti mansoni, who have been treated in the Clinical Hospital of Guanabara University so far. The patients come from the endemical areas of the country, specially from northeast and southeast, being $53,9 \%$ males and $46,1 \%$ females, aged between 5 and 63 . The prevailing clinical form of the parasitosis was the hepatic-intestinal $(96, \%)$. The medicine has been applied in a single dosage, at the rate of $3 \mathrm{mg} / \mathrm{kg}$ of body weight, $336 \%$ in in- patients and $66,4 \%$ at the stage of ambulatorial treatment. The serum levels of the transaminases determined for comparison before and after the use the product, in 60 of the in-patients, did not modify, or just suffered inexpressive raising. There were no side-effects in $42.3 \%$ of the patients. In the others, those effects were of little and meoium intensity and lasted only the first day in most cases, and consisted specially of nauseas and vomits. The parasitical cure control was performed through 4 stool examinations, at the end of $30,60,90$ and 120 days of the medicine employment, and it has been done in 330 patients $(33 \%)$, with $99 \%$ of cure. By including the rectal biopsy whenever it was possible, by the time of the 4th stool examination, the procedure had worked out well with 97 patiens $(9,7 \%)$, and among them 92 (94\%), are now cured, according to that criterion. This paper confirms the schistosomicidal activity of the Hycanthone, as well as its good tolerance, including regarding the hepaitic cells. The patients, however, must be carefully selected, taking into account the known counter-indications, mainly concerning the liver.

\section{REFERÊNCIAS BIOGRÁFICAS}

1 - ANDRADE, Z., SANTOS, H. A., BOREJOVIC, R. \& GRIMAUD J. A. Lesôes hepáticas produzidas pelo Hycanthone. $x$ Cong. Soc. Bras. Med. Trop. Curitiba, 1974.

2 - ARGENTO, C. A., NEVES, P. F., GALVÃO, F. A., PENNA, D. R. \& SILVA, J. R. - Novos esquistossomicidas. Rev. Soc. Bras. Med. Trop. 1: 37-48, 1967.

3 - BINA, J. C. \& PRATA, A. - Hycanthone no tratamento da esquistossomose em uma área rural com baixo indice de transmiscão da donnça. Gaz. Med. Bahia, 70: 127-130, 1970.

4 - BRENER, Z. Contribuição ao estudo da terapêtica experimental da esauistossomose mansoni. Tese. Belo Horizonte, 1962 .

5 - BUEDING, E. - Mechanisms of action of schistosomicidal nof wts .T. Pharmacy \& Pharmacol. 11: 385-392, 1959.

6 - CHRISTOPHERSON, J. B. - The successful use of antimony in bilharziasis administered as intravenous infections of antimony tartaratum. Lancet 2: 325-327, 1918.
7 - COUTINHO, A. - Present status of the treatment of schistosomiasis manson', Rev Inst. Med. 'Irop. São Paulo 11: 363-376, 1969.

8 - CUNHA, A. S. \& CANÇADO, J. R. - Avaliação terapêutica do Win 24.933-2 (derivado hidroximetil do Miracil D) e do A-16.612 (composto de piperazina) na esquistossomose mansoni humana pelo método do oograma quantitativo. Rev. Inst. Med. Trop. São Paulo 10: 118-123, 1963.

9 - CUNHA, A. S. - Tratamento clínico da esquistossomose. In Esruisros: omose Mansoni. Ed. Univ. São Paulo, 1970 .

10 - DENNIS, E. W. \& ARCHER, W. $\mathbf{s}$. - Chemotherapy of schistosomiasis (past and present) with special reference to Hycanthone. A Summary. Proc. II Simpósio sobre esquistosscmose. Salvador, 1970.

11 - DODIN. A., MOREAU, J. P. \& RETOVON-DRAHETY. - Perspective d'avenir en ce qui concerne le traitement et la profilaxie de la bilharziose. Bull. Soc. Path. Exot. 59: 106-109, 1966. 
12 - FIGUEIREDO, J. F. M. \& PRATA, A. - Eficácia do Hycanthone no tratamento da esquistossomose mansoni. Gaz. Med. Bahia. 69: 16-19, 1969.

13 - JORGE, F. C. - Considerações clínico-laboratoriais sobre um caso de hepatite tóxica medicamentosa pelo Hycanthone com esquema posológico de $3,5 \mathrm{mg} / \mathrm{kg}$ - dose única. X Cong. Soc. Bras. Med. Trop. Curitiba, 1974.

14 - KATZ, N. \& PELLEGRINO, J. Ensaio laboratorial e clínico com Hycanthone. Novo agente esquistossomicida. Rev. Bras. Med. Trop. 1: 219-230, 1967.

15 - KHIKUTH, W. \& GONNERT, R. Experim ntal studies on the therapy of schistosomiasis. Ann. Trop. Med. Parasitol. 42: 756-567, 1948.

16 - MANSOUR, T. E. \& BUEDING, E. The actions of antimonials on glycolytic enzymes of Schistosoma mansoni. Brit. J. Pharmacol. 9: 459-462, 1954.

17 - NOLETO, P. A., CARNEIRO F', D. A., BRANDĀO, E. D. \& TUMA, M. - O emprego do Niridazol na esquistossomose mansôsino. A Folha, Med. 57: 245-255, 1968 .

18 - PASSOS, J. N., BALDY, J . L. S., SIQUEIRA, L. T., SOARES, E, C. ZEITUNE, J. M. R. \& REIS, S. R. Estudo eletrocardiográfico seriado de 80 casos de esquistossomose mansônica - Fase crônica - tratados com Hycanthone. $\mathrm{X}$ Cong. Soc. Bras. Med. Trop. Curitiba, 1974.

19 - RODRIGUES DA SILVA, J. - Quimioterapia por via oral na esouistossomose mansoni. Tese. Rio, 1955.
20 - ROSI, D., PERUZZOTTI, G., DENNIS, F. W., BERBERIAN, D. A., FREELE, $H$. \& ARCHER E. - A new active metabolite of "Miracil D'. Nature 208: 1005-1006, 1965.

21 - ROSI, D., PERUZZOTTI, G., DENNIS, E. W., BERBERIAN, D. A., FRELE, H., 'TULLAR, B. $\mathrm{H}^{\prime}$. $\%$ ARCHER, S. - Hycanthone, a new active metabolite of Lucanthone. Jour. Med. Chem. 10: 867-876, 1967.

22 - SAlgado, J. A., VEloso, C., OLIVEIRA, C. A., CHAMONE, D. A. F., LEMOS, M. S., KATZ, N. \& PELLEGRINO, J. - Alterações eletrocardiográficas observadas em pacientes com esquistossomose mansoni tratados com um derivado niaroximeuilicc do Miracil D (Hycanthone). Rev. Inst. Med. Trop. S. Paulo 10: 312-315, 1968.

23 - SANDIA, O. G. \& AGUIRRE, G. H. - Controle da esquistossomose mansoni pela terapêtica oral na população de Santa Clara (RJ). Avaliaçäo preliminar - abril, 1969, agosto, 1970. Proc. XVIII Cong. Bras. Hig. São Paulo, 1970.

24 - STANDEN. O. D. - Experimental schistosomiasis III. Chemoterapy and mode of drug ction. Ann. Trop. Med. Parasitol. 47: 26-43, 1953.

25 - STANDEN, O. D. - The treatment of experimental schistosomiasis in mice: sexual maturity and drug response. Ann. Trop. Med. Parasitol. 49: 183-192, 1955.

26 - STFRNG - WINTHROP RESEARCH INSTITUTE. A summary of laboratory data on Hycanthone (Win 24 9332), a schistosomicidal agent. Rensselaer, New York, 1964. 